$\mathrm{Oz}$

Volume 25

Article 6

$1-1-2003$

\title{
A Message from the Desert
}

Luis Ibarra

Teresa Rosano

Follow this and additional works at: https://newprairiepress.org/oz

(c) $($ ) $\Theta \Theta$

This work is licensed under a Creative Commons Attribution-Noncommercial-No Derivative Works 4.0 License.

\section{Recommended Citation}

Ibarra, Luis and Rosano, Teresa (2003) "A Message from the Desert," Oz: Vol. 25. https://doi.org/10.4148/ 2378-5853.1383

This Article is brought to you for free and open access by New Prairie Press. It has been accepted for inclusion in Oz by an authorized administrator of New Prairie Press. For more information, please contact cads@k-state.edu. 


\title{
A Message from the Desert
}

\author{
Luis Ibarra and Teresa Rosano
}

We were shot in the middle of the desert by a hippie chick in a van. Actually it was a photo-shoot for Architecture Magazine last year. We were one of nine architecture design firms chosen by the magazine and told to meet in the parking lot of a Quick Mart in Apache Junction, Arizona, about thirty miles east of Phoenix. Riding in the van, on the way to the location, the architects joked of a probable plot to lure Arizona's modern architects to the middle of nowhere and get rid of them once and for all. Bumping our heads as we wound down dirt roads, we finally arrived at the base of the Superstition Mountains east of Phoenix. Fortunately, it was not a plot, but an actual photographer with a real camera. We filed out of the van and stood facing the breathtaking view of the mountains with low desert scrub behind us. Explaining that she wanted to capture a bleak patch of scrub desert to illustrate that the desert is a desolate place in need of design, the camera faced us, and the mountain peak never made it into the photo. She posed an interesting artistic statement but not an entirely true one.

Arizona is a unique environment rich with beauty. It does need good design, not because it is devoid of character but because it is full of integrity and strength, qualities lacking in many of Arizona's buildings. Repeatedly, outsiders have come here with alien architectural ideas and plopped them success. We are natives of the Sonoran Desert. Specifically, we are natives of Tucson and graduates of the University of Arizona, and have seen the effects of designing without an understanding of place. At a time when it seems like a right of passage to leave the state after graduation, Arizona natives seem rare. While attending the University of Arizona, Luis studied with Australian architect Glenn Murcutt, whose design philosophy struck a chord; Murcutt explained that great architecture is born from a strong understanding of place. With these words in mind, we made a conscious decision and stayed in Tucson to practice. We understand this place and feel we have much to do for this land. In Leaves of Iron Philip Drew states, "The house is man-made, it is the intruder, and man must make his peace. Man's invasion of nature calls for a delicate touch and a reverence for those things which are part of nature." It is with this sense of responsibility that we work to protect the vegetation, fauna and landforms in the fragile desert while creating spaces for human dwelling.

To explore our own architectural ideas, we bought a small concrete block "box" on a large midtown lot and began our first design-build project-our own residence and studio. After a year and a half of tired backs and bruised knuckles from evenings and weekends of construction, we submitted our first finished room, the kitchen, to a national design competition. To our
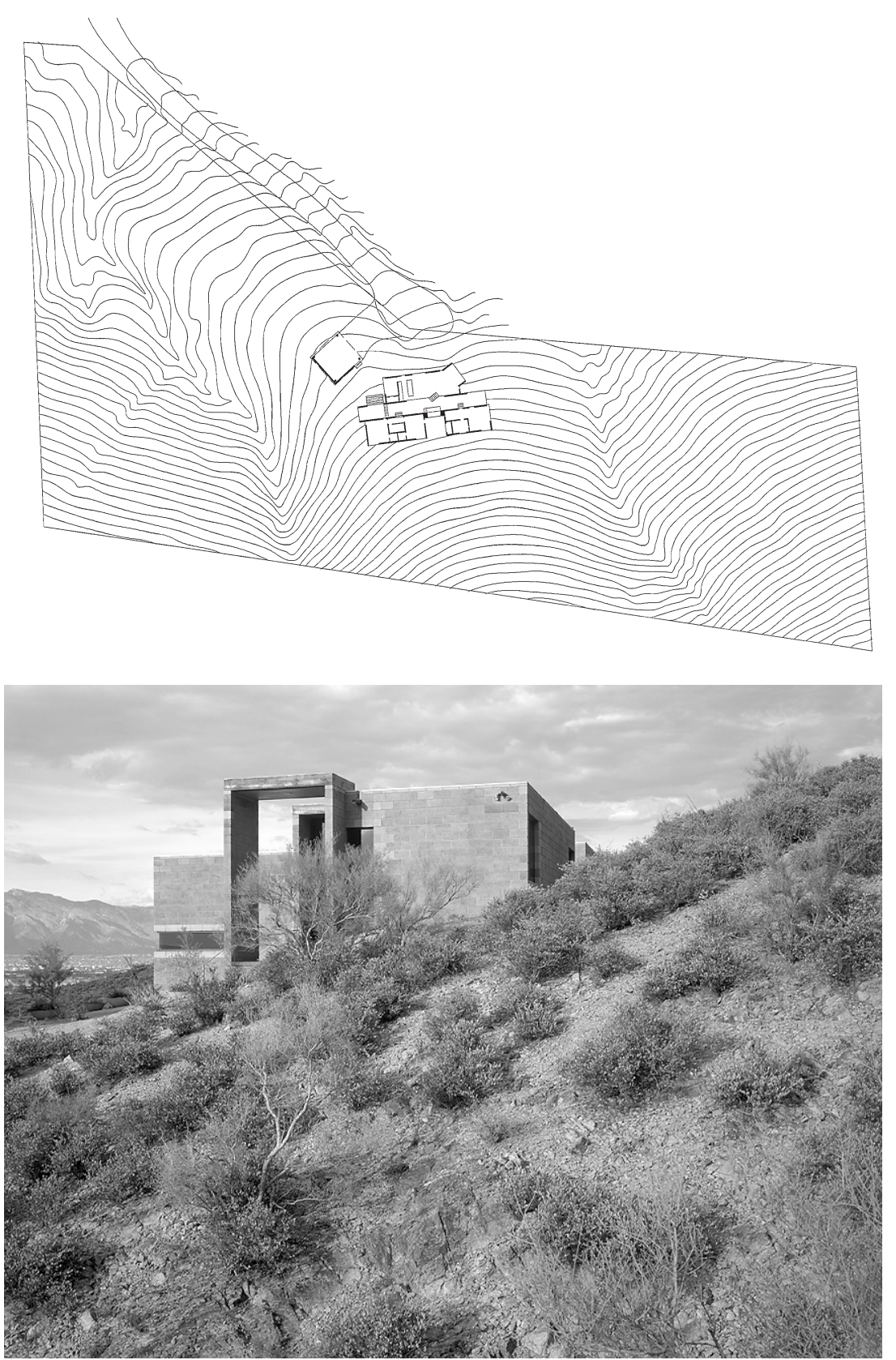


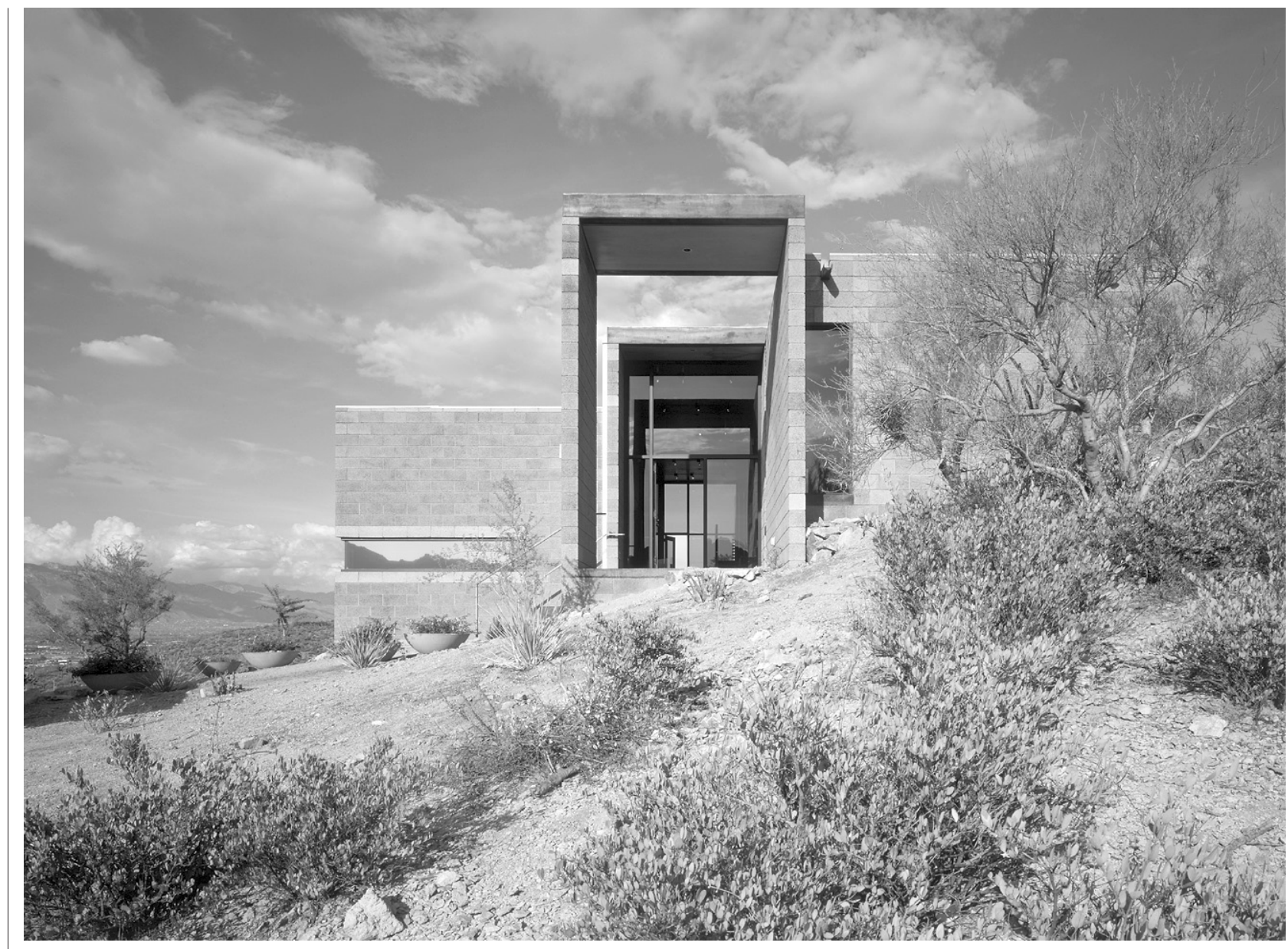

surprise we won the Grand Prize: a new fully-loaded mini-van, which we sold to buy computers and launch our practice. Soon thereafter, we received our first freestanding house design commission: the Garcia Residence.

It is our design approach to search for the inevitable solution, reducing elements to their essence without being preoccupied about being minimal-a lesson seen in the nature of the desert that surrounds us. In this arid region plants do not waste precious water and energy on big floppy leaves. The thin leaves of the mesquite and the waxy coating of cacti protect against excessive transpiration during long dry periods. During the brief but intense monsoon season, the long-reaching capillary root system of the saguaro gathers enough rain to be stored for many months. Even the "horns" of the horned lizard are designed to direct rain to its mouth for drinking. The flora and fauna of the desert are efficient and conserving. We use nature's intuitive knowledge to design for this place, our clients and ourselves.

The Garcia site is west of the city: a steep north-facing slope in the foothills of the Tucson Mountains with commanding views of the Catalina Mountains and city lights. Upon first walking the site, we noticed instantly that solid rock lay just below the surface. We knew the rocky hillside would present a challenge and excavation would be expensive. Our first challenge was to design a structure that would appear to grow out of the desert hillside without dominating the landscape, not an easy task since the site is covered in low-lying vegetation and earth integration was out of the question. The second chal- lenge was to create an extraordinary space with ordinary materials. As is our standard, we spent a great deal of time on the site getting familiar with the landscape's sightlines, topography, plants, animal crossings, winds and breezes, and solar angles before beginning any design work.

The developments surrounding the Garcia residence are typical of Tucson. It is common to see a bulldozer stripping the desert clean of everything that makes it beautiful. Either for ease or laziness, sloped sites are usually filled with dirt imported to create a flat pad on which to plop cookie-cutter designs. Fortunately, without convincing, our client was ready to adapt the house to the site, and not the other way around. Using the flattest area of the site for the cars and carport, we positioned the house close to the drive. We set
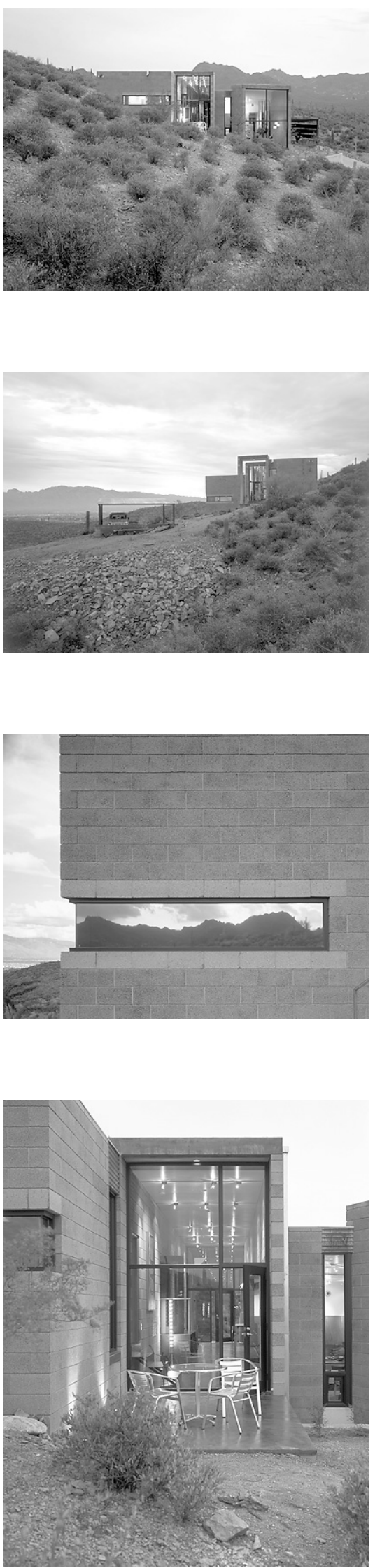

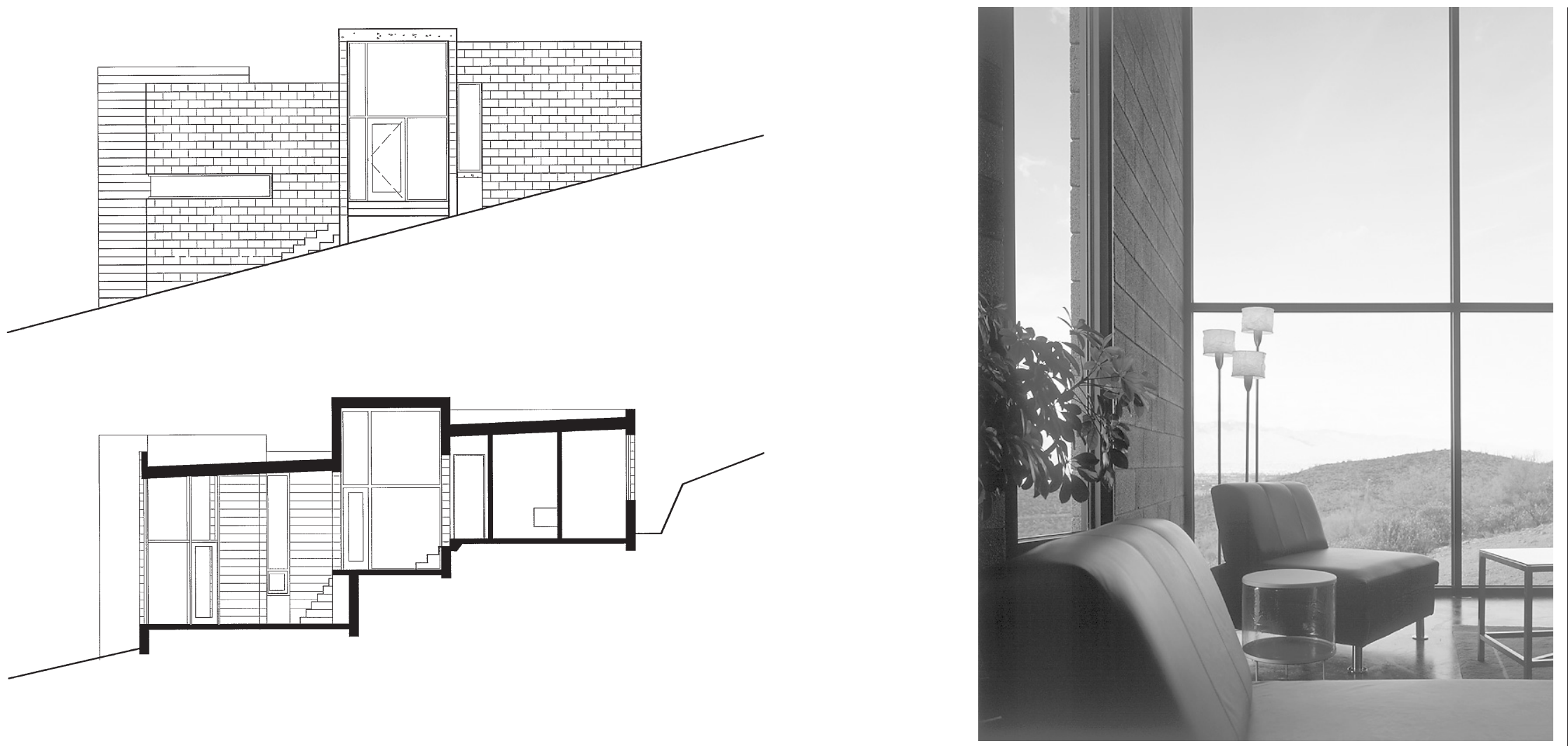

the axis of the house parallel with the site contours and created three narrow bays to terrace up the hill, keeping the excavation and fill to a minimum. The terracing platforms contain the three zones of the house: living, circulating and sleeping. In order to keep the 2,150 square-foot footprint compact, we did not waste space with hallways. We used the middle bay, the entry "gallery," for both circulation and as an extension of the living spaces. The gallery is conceived as a tube-like space open at each end to frame the desert beyond, axially aligned with nearby mountain peaks to the west and saguaro views to the east. It invites the visitor down to the living, dining and kitchen spaces on the lowest platform, while connecting the house to the bedrooms on the upper level.

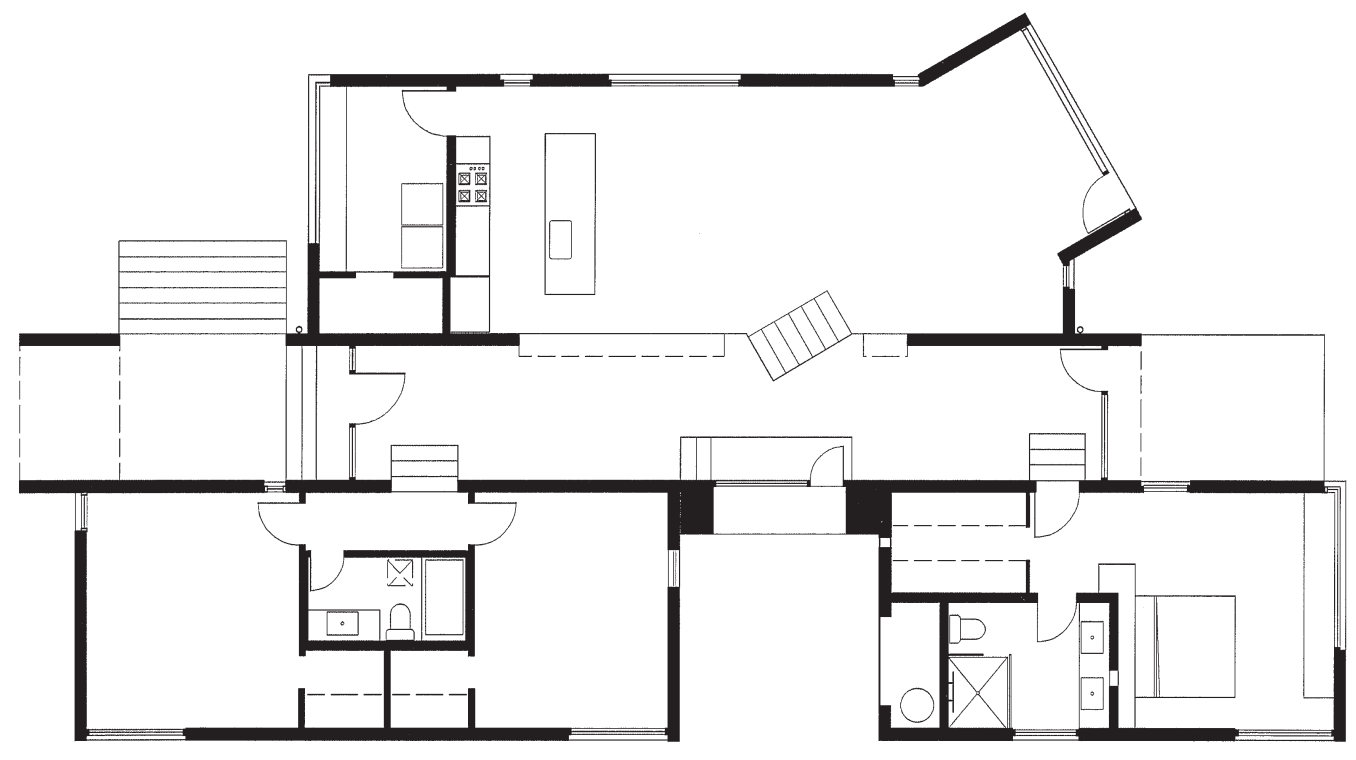

The residence is intentionally loft-like, per the owner's request. The outstanding city view led us to break the house axis and rotate the main window to 

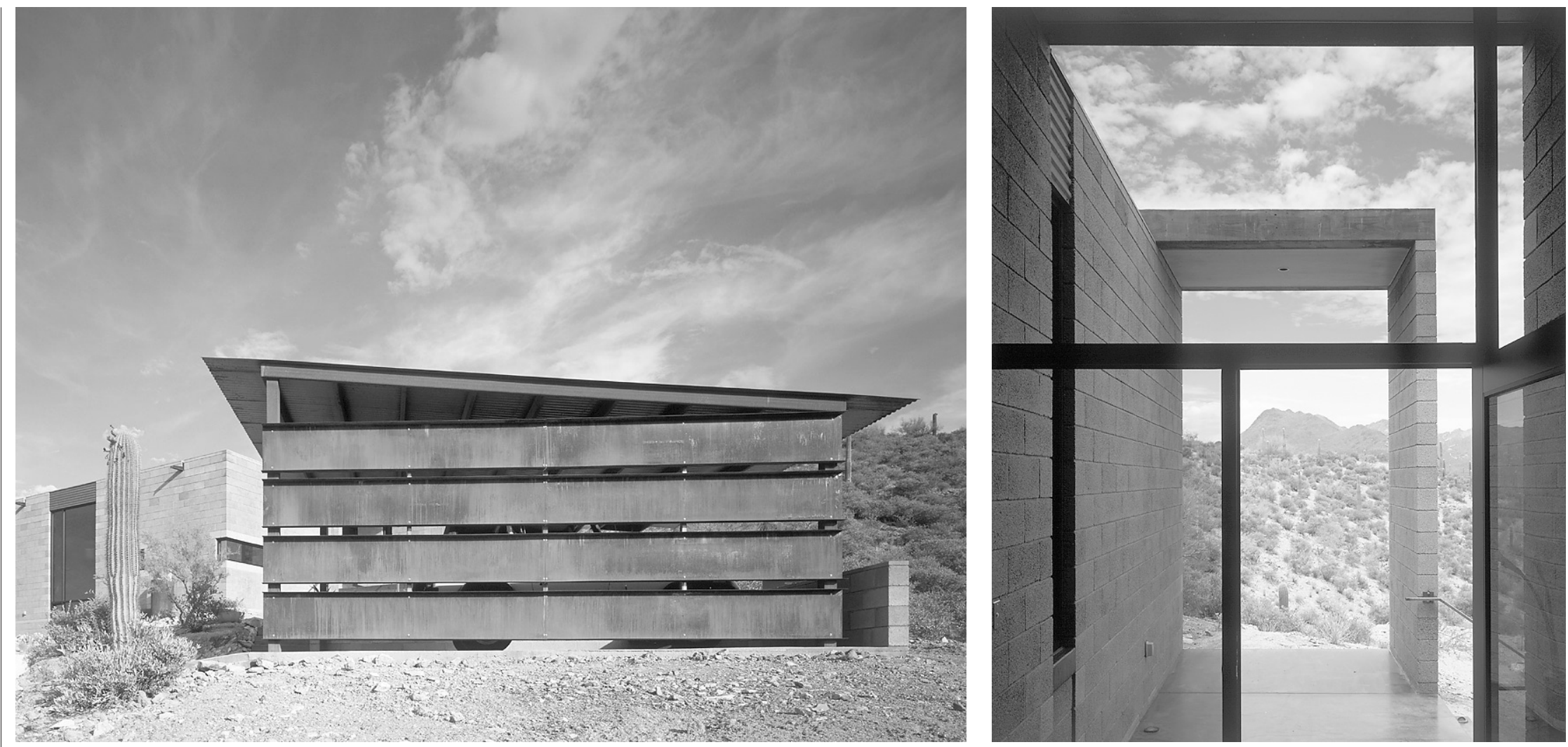

frame fantastic views of the Tucson city lights and the Catalina Mountain to the northeast. Here, the edge of the dwelling meets the desert floor, giving inhabitants a feeling of shelter and a connection to the land, from the distant mountains to the nearby flora. Regularly, a resident pack of javelina, a wild pig-like animal, comes into the foreground to peer through the window at the owners.

We were able to introduce southern sun to the living spaces by splitting the bedrooms apart, thereby creating a small intimate courtyard. The courtyard serves as a sheltered, shaded exterior room with a view up the ridge and a secret garden with brightly painted fuchsia walls and colorful bougainvillea. It invites warm solar rays in the winter, while in the summer it provides passive cooling for the house when the heavier cool air falls down the mountain through open windows in the courtyard into the house and out openings on the lowest level.
The material palette is simple, durable and responsive to the desert climate colors and textures. The walls are Integra Block, an insulated concrete block system. Sandblasted, the block is the finish material inside and out, intentionally blurring the distinction between interior and exterior. The natural gray color complements the gray-green jojoba bush covering the hillside. Rusted steel echoes the iron oxide coloring found in the fieldstone while steel plate steps zigzag between the different dark gray concrete floor levels with birch plywood cabinets providing function and warmth.

Although the resultant form may be pleasing, it is our belief that architecture is space rather than form. Architecture does not begin when the first block is laid, rather it exists everywhere, all the time. The space beneath a desert tree, with dappled light shifting against the cooled soil at its roots, is a marvelous form of architecture in the heat of summer. This shelter provided by a native mesquite is, in fact, the nursery to many infant saguaro.

The saguaro cactus, the best-known symbol of Arizona, is unique to the Sonoran Desert and grows very slowly at less than one inch per year. Saguaro have a stillness and sense of permanence. We never move a saguaro, as they have less than a fifty percent survival rate at heights of ten feet or more. It has always felt wrong to move them, almost like the idea of moving ancient burial sites. Since they were here first, we must respectfully work around them. At the Garcia site, there was once a twentyfoot-tall saguaro in poor health that stood between our proposed design for the house and carport. In spite of its questionable appearance we carefully designed around it. The contractor, Page Repp, and his excavator meticulously excavated around it. About the time the rough plumbing was going in, Page called Teresa's cell phone and said, "You know that dying saguaro near the corner? Well, you don't have to worry about it any more." Teresa's immediate reaction was, "Oh no! You hit it!" "No", explained Page, "as the plumbers were walking toward their truck, about ten feet away from the saguaro, lightning struck it! (Southern Arizona is known for its incredible lightning displays and home to extensive lightning research.) The fortunate irony is that if the saguaro hadn't been there, the plumbers would have been the tallest objects on the hill. We had saved the saguaro's life and the saguaro saved the plumbers. Saguaro karma? If it is, some Arizona developers should be worried.

\section{Project Credits}

Architect: Ibarra Rosano Design Architects Luis Ibarra and Teresa Rosano (principals)

Consultants: Paul Formentini (mechanical, electrical), Ross Mellencamp (plumbing) Engineers: Nichols On-site Engineering (civil), Pattison Evanoff (geotechnical), Caruso Turley Scott (structural-Integra wall system)

Contractor: Repp Construction

Furnishings: City Home Furnishings Photos: Bill Timmerman 